\title{
Hannah Arendt lectora de Kant 1
}

\author{
Paula Hunziker \\ paulahunziker@hotmail.com \\ Universidade Nacional de Córdoba, Cordoba, Argentina
}

resumen La presente investigación, centrada en el pensamiento de Hannah Arendt, está orientada a mostrar la importancia de la reflexión arendtiana acerca del totalitarismo para analizar el contexto y las tensiones de su asimilación tardía de la filosofía kantiana -especialemente de la Kritik der Urteilskraft- durante los años sesenta y setenta. Ello no implica desconocer ciertos desplazamientos con respecto a la evolución de este tema en la obra de nuestra autora, sino más bien que los mismos se dan en el interior de un continuum. De acuerdo con esto la facultad de juzgar es el intento, siempre inconcluso, de pensar la figura política del espectador y su peculiar autonomía; la política del espectador.

palabras clave Arendt; Kant; juicio reflexionante; totalitarismo; comprensión; espectador

En una carta de 1957 a Karl Jaspers, Hannah Arendt expresa con entusiasmo un modo de lectura de la obra de Emmanuel Kant que se irá afianzando en las dos décadas siguientes: "En este momento estoy leyendo con creciente entusiasmo la Crítica del juicio. Es ahí y no en la Crítica de la Razón Práctica, donde se encuentra la verdadera filosofia política de Kant. El himno de alabanza al tan difamado sentido común, el fenómeno del gusto como manifestación básica de la facultad de juzgar (...) considerado con toda seriedad filosófica; el modo de pensar ampliado, que forma parte del juzgar, y por el cual uno puede pensar en el lugar de todos los demás. La exigencia de la comunicabilidad" (ARENDT/ JASPERS, 1992, p. 318)

¿Cuáles son los efectos de la lectura de la Crítica de la Facultad de Juzgar kantiana en el cuerpo del texto de la pensadora judío-alemana? Respon- 
der a esta pregunta es una tarea compleja -que invita a la interpretación desde el comienzo-. Pues si bien podemos afirmar que es uno de los temas centrales de los años sesenta y setenta, las afirmaciones arendtianas respecto de la actividad de juzgar se hallan dispersas en artículos y en clases no publicadas orientadas a pensar fenómenos políticos con el juicio -más que a reflexionar sobre sus características en tanto "facultad". En este marco no deja de congruente con el carácter elusivo de este tema, el hecho de que "El Juicio" sea el capítulo inconcluso de su opera póstuma, La vida del espíritu².

El presente artículo parte de la hipótesis metodológica de que una forma fructífera de abordar la pregunta por el diálogo de Arendt con Kant consiste en comprender el lugar, las experiencias y las preguntas desde las cuales nuestra pensadora se encuentra con el filósofo alemán; interpreta y extrapola -en el presente- la obra kantiana.

En este marco, sostenemos que la experiencia que está en la base de la meditación sobre el juicio es el suelo inestable conformado por los dilemas abiertos al concluir Los Orígenes del Totalitarismo. Ello no implica desconocer ciertos desplazamientos con respecto a la evolución de este tema en la obra de nuestra autora, sino más bien que los mismos se dan en el interior de un continuum. De acuerdo con esto la facultad de juzgar es el intento, siempre inconcluso, de pensar una figura que si bien sólo durante los sesenta empieza a despuntar con tal nombre, se dibuja en su obra desde la finalización de aquel libro: la figura política del espectador y su peculiar autonomía; la política del espectador ${ }^{3}$.

En este marco, la figura del espectador es la cifra de una respuestaúltima y no concluida- para un tema que flota si resolverse en ninguno de sus grandes libros: ¿es posible un pensamiento de lo político? ¿bajo qué modalidades?

\section{Comprensión y política: bajo la sombra totalitaria}

Con el significativo título "Comprensión y Política", Hannah Arendt intenta pensar por primera vez, en 1953, la figura del "juicio". En este horizonte, la figura kantiana es evocada casi con patetismo: “¿La comprensión no está tan íntimamente relacionada con el juicio que 
debería describirse a ambos como la capacidad de subsumir (lo particular a una regla universal), que según Kant es la definición misma de juicio y cuya ausencia definió magníficamente como 'estupidez', enfermedad sin remedio?" (ARENDT, 1994b, p. 39).

Más que en la pregunta, el tono dramático se encuentra en su contexto de enunciación. Pues se trata de comprender el totalitarismo, un abismo que ha iluminado la ruina de nuestras categorías de pensamiento político y de nuestros criterios para el juicio moral.

Por otra parte, si bien nos enfrentamos con un acontecimiento que desafia de modo radical nuestra posibilidad de comprensión, "aun si hemos perdido las varas para medir y las reglas para subsumir un particular, un ser cuya esencia es comenzar puede tener en sí suficiente origen como para comprender sin categorías preconcebidas y para juzgar sin el conjunto de reglas tradicionales de la moralidad" (ARENDT, 1994b, p. 50).

Según el tortuoso desarrollo del artículo, la mentada "originariedad" de la comprensión y el juicio se ligan a la posibilidad de generar un "sentido" para lo acontecido, lo que implica generar un sentido para la "acción". En este marco debería entenderse la idea de que "la comprensión es la otra cara de la acción”, concepto que en 1953 Arendt está empezando a pensar como el centro de la política en tanto comienzo: "la acción política, como toda acción, esencialmente es siempre el comienzo de algo nuevo, como tal es, (...) la esencia misma de la libertad humana" (ARENDT, 1994b, p. 49).

Ahora bien: ¿Qué significa comprender y juzgar "originariamente”? De modo significativo, la posibilidad de comprender y juzgar la acción como novedad, como libertad, culmina con un elogio del lazo que une a la comprensión con el don de la libertad de la imaginación, "que nos permite ver las cosas (...) sin parcialidad ni prejuicio” (ARENDT, 1994b, p. 51), al establecer una distancia respecto a lo más cercano y una cercanía respecto a lo lejano.

Más bien enunciada que explicada, esta afirmación deja en suspenso el modo en que deba entenderse la "cercana lejanía" de la imaginación. Subsidiariamente deja abierta otra cuestión: ¡cuál es el espacio que hace posible la propia mirada arendtiana?

Algunos indicios sobre este problema surgen en las pocas aclaraciones que Arendt realiza respecto del "método" seguido en Los 
Orígenes del Totalitarismo. Criticada - con razones exactamente inversaspor historiadores y filósofos, nuestra pensadora defiende su enfoque en varios frentes.

Por una parte, indica, ha buscado evitar una "historia de las ideas" -tal como señala replicando a Voegelin la tesis del totalitarismo como desarrollo inevitable de la herejía inmanentista moderna (ARENDT, 2005a, p. 488)-, pero también una "historia de los hechos" -tal como advierte ante un concepto positivista ingenuo de experiencia histórica ${ }^{4}$.

Por otra parte, ha buscado evitar el moralismo y el sentimentalismo en el estilo, pero también la neutralidad abstracta del concepto. Es en este marco, central para entender su posterior entusiasmo por la estética kantiana -y por la imparcialidad ligada a la facultad de juzgar-, que emerge su defensa de la metáfora, de la imaginación y de la pasión como herramientas para una comprensión "objetiva". Una descripción de los campos de concentración -señala Arendt- que deja de lado aquello que en el objeto suscita la indignación es "menos objetiva", dado que, en ese caso, lo que "yo hago es elevar este fenómeno humano fuera de su contexto en la sociedad humana, con lo cual lo he desposeído de parte de su naturaleza”. En este marco, Kant nos enseña un modo de pensar la imaginación -culmina la autora- en tanto herramienta genuina de cognición: una Einbildungskraft "que nada tiene que ver con la habilidad para la ficción" sino más bien con la facultad humana de "dar respuesta" a lo que nos sucede (ARENDT, 2005a, pp. 486-488).

Finalmente. El libro ha intentado tomar distancia tanto del uso de la "causalidad"-categoría portadora de una continuidad que "sólo está justificada si el autor quiere preservar" y "justificar lo que ha sucedido"- así como de la simple condena de los hechos, que sólo sería permisible en el marco de "un suelo firme de valores tradicionales, aceptados sin reservas" (YOUNG-BRUEHL, E., 1993, p. $263^{5}$ ), suelo que el totalitarismo ha vuelto imposible.

Así explicitadas, estas alternativas definen el espacio que hace inteligible el gran dilema planteado en el Prólogo a la primera edición norteamericana de Los Orígenes del Totalitarismo. Según nuestra perspectiva, comprender la función del juicio en la obra de Arendt es comprender en qué medida involucra un camino -sinuoso- para avanzar en la tarea trágica de "examinar y soportar conscientemente la carga que nuestro siglo ha 
colocado sobre nosotros -y no negar su existencia ni someterse mansamente a su peso" (ARENDT, 1994a, p. 10).

\section{Polis y Crisis: la diferencia kantiana}

Retomemos ahora el entusiasmo por Kant expresado en la carta de 1957. En principio, la misma carta nos da indicaciones precisas sobre su "situación de tránsito". Efectivamente, tal como relata Arendt a Jaspers, el entusiasmo por el filósofo alemán aparece "en las vacaciones que me he dado entre la finalización del libro para Chicago y el comienzo de la introducción a la política para Piper" (ARENDT/ JASPERS, 1992, p. 318). El primer libro mencionado, es La Condición Humana. El segundo, una "Introducción a la Política" que Hannah Arendt nunca concluirá6, pero cuyos esbozos -conservados en los Archivos Arendt y publicados por Ursula Ludtz bajo el título ¿Qué es Política? -constituyen un documento central para analizar el contexto de su recepción de Kant.

Dar inteligibilidad a este "tránsito" (al menos en su relevancia para el tema del juicio), requiere detenernos en lo que consideramos un "desequilibrio" del enfoque general de La Condición Humana. Si bien este texto -producto de una intensa reflexión en torno a dos conceptos dominantes durante los cincuenta: el concepto de "acción" como locus de la política y el de "esfera pública" como su topos privilegiado-, pone en cuestión la jerarquía que conduce a la reflexión filosófica de lo político a no percibir el reino de la acción sino a partir de las condiciones de la vita contemplati$v a$, no parece dejar una perspectiva clara acerca de qué lugar corresponde al "pensamiento" una vez puesta en cuestión aquella distinción jerárquica (ARENDT, 1993, pp. 28-30).

En este marco, las referencias al narrador clásico -en tanto portador de una mirada alternativa respecto del espectador filosófico de la política (Cf. ARENDT, 1993, pp. 205-211)-, apuntan más bien a un problema que a una solución; pues si bien Arendt parece sugerir que ciertas características del mismo permiten un modo de abordar lo político -la imparcialidad homérica- que hace "justicia" a su "objeto", la autora es conciente de su dependencia respecto al paradigma de la polis griega ${ }^{7}$-paradigma que precisamente no puede suponer una vez acontecido el "fin de la tradición". 
Es justamente la conciencia de este problema la que aparece en los esbozos conservados del proyecto para una Introducción a la Política. Por un lado, es innegable que allí la propia reflexión acerca de la facultad de juzgar y su politicidad contiene referencias a la experiencia política clásica, en tanto suelo de una capacidad -para "ver los temas desde distintos lados"- visible en la imparcialidad homérica y luego transpuesta en una facultad "para intercambiar el propio y natural punto de vista, con el de los demás junto a los que se está en el mundo", tal como se desarrolla en un espacio político deliberativo clásico. En tal espacio, los “objetos”, al ser "tratados por tantos en la presencia de otros muchos, son sacados a la luz de lo público, donde están obligados a mostrar todos sus lados" (ARENDT, 1997, p. 111).

Ahora bien: ¿cómo hacer inteligibles las referencias a la facultad de juzgar kantiana, tal como son desarrolladas en estos esbozos? Según nuestra perspectiva, la introducción de la resonancia kantiana en el marco de una "facultad clásica", es una indicación importante respecto de los problemas y las experiencias contemporáneas que subyacen a su tematización del juicio: incluso en sus primeras reflexiones respecto de este tópico (en donde Arendt explícitamente compara la facultad de juzgar con la phrónesis aristotélica), la experiencia a partir de la cual intenta pensar la potencialidad política de la facultad de juzgar es un presente interpretado como "crisis sin precedentes del juicio", como "crisis histórica en donde los prejuicios se tambalean” (ARENDT, 1997, p. 54). Respecto de esta territorialidad, Arendt establece una distinción central: más que de una crisis del juicio como tal, de lo que hablamos es de la "imposibilidad de juzgar lo que ha sucedido y sucede cada día según unos criterios firmes y reconocidos por todos, de subsumirlo como caso de un universal bien conocido, unida estrechamente a la dificultad de ofrecer principios de acción para lo que deba suceder" (ARENDT, 1997, p. 55). Esta descripción que une al mundo contemporáneo con la época moderna, sólo es pensable bajo la categoría de "nihilismo" -señala Arendt- si aceptamos que "a los hombres se les puede exigir juzgar cuando poseen criterios".

En este espacio problemático se hace inteligible la apelación a Kant, en cuyo concepto de "juicio" la pensadora encuentra, además de una serie de vinculaciones con la tradición tópico-retórica clásica, una novedad ligada a la radicalidad que lee en la "autonomía" del juicio estético. Es precisa- 
mente el pensador alemán quien ofrece a Arendt la posibilidad de pensar en una facultad que "consiste y debe consistir en juzgar directamente y sin criterios" y que debería tomarse tan en serio en el ámbito de la estética, cuanto en el de la política -en tanto espacios en donde "lo juzgado no tiene nunca carácter concluyente, nunca obliga a los demás en el sentido en que una conclusión lógicamente irrefutable obliga al asentimiento, sino que sólo puede persuadirles" (ARENDT, 1997, p. 55).

Por esta razón, creemos, es estéril y no facilita la comprensión de la obra arendtiana, contraponer temporalmente un primer momento "clásico" en la reflexión acerca del juicio y un segundo momento "moderno". En un contexto de "pérdida de criterios, que de hecho determina al mundo moderno en su facticidad y que no es reversible mediante ningún retorno a los buenos Antiguos o al establecimiento de nuevos valores y criterios" (ARENDT, 1997, p. 56), se explica la coexistencia inestable de los dos grandes aspectos de la facultad de juzgar, tal como son desarrollados en este texto inconcluso: el componente "deliberativo" y el componente "crítico-reflexivo" (que Arendt describe teniendo en cuenta la estética kantiana).

El hilo conductor es la interpretación arendtiana de la distinción kantiana entre juicio determinante y juicio reflexionante (KANT, 1991, Segunda Introducción, IV, p. 90). Existen dos significados para la palabra juzgar: "por una parte alude al subsumir clasificatorio de lo singular y particular bajo algo general y universal, al medir, acreditar y decidir lo concreto mediante criterios valorativos". Este tipo de juicio no tiene sentido en el contexto indicado, dado que en este caso "sólo se juzga lo individual pero no el criterio ni su adecuación a lo que mide". En una época de "crisis" -y aquí hay que entender, en una época sin criterios establecidos- se requiere otro tipo de juicio, cuya principal virtud consiste en su "espontaneidad" y su "originariedad": "Juzgar puede aludir a algo completamente distinto: cuando nos enfrentamos a algo que no hemos visto nunca y para lo que no disponemos de ningún criterio. Este juzgar sin criterios, no puede apelar a nada más que a la evidencia de lo juzgado mismo y no tiene otros presupuestos que la capacidad humana del juicio" (ARENDT, 1997, p. 54).

En este marco, Arendt deja en claro que la fuente principal para este tipo de juicio es Kant: "Este juzgar sin criterios nos es bien conocido por 
lo que respecta al juicio estético de gusto (Geschmacksurteil), sobre el que, como dijo Kant, precisamente no se puede 'disputar' pero si discutir ${ }^{8}$ y llegar a un acuerdo" (ARENDT, 1997, p. 54).

Por último, es la distinción entre discusión y disputa aquello que ilumina el carácter esencialmente deliberativo del juicio, y lo que conduce a Arendt a pensar las afinidades entre la "libertad de espíritu" de la facultad de juzgar en sentido estético y la phronesis aristotélica: "(sobre la phronesis) apenas se ha hablado durante siglos. Es en Kant en quien la reencontramos en primer lugar, en alusión al sano entendimiento humano como una facultad de la capacidad de juicio. La llama 'modo de pensar ampliado' y la define explícitamente como la 'capacidad de pensar desde la posición de cualquier otro"” (ARENDT, 1997, p. 111-112).

Ahora bien. Si consideramos que la "diferencia" kantiana -ligada a la articulación entre deliberación y reflexión- es lo que desde el inicio atrae a Arendt hacia la facultad de juzgar como tal, ello indicaría que la "distancia crítica" del juicio -su independencia- es uno de los atractivos fundamentales para Arendt, incluso definitorios de su "politicidad", desde el comienzo.

El punto fundamental, a nuestro entender, no es decidir si el juicio corresponde a, o es el privilegio del actor o del espectador, sino más bien comprender la distancia posibilitada por el mismo. El juicio es la posibilidad de una distancia -y en ese punto es siempre juicio del espectador. Lo central es el carácter potencialmente "político" de la misma.

Según nuestra hipótesis, por tanto, existe una continuidad en la reflexión arendtiana acerca del juicio, así como un progresivo enriquecimiento -no un empobrecimiento- de su potencialidad política, durante los setenta y sesenta. En este marco, consideramos que Eichmann en Jerusalen así como las Conferencias sobre la Filosofía Política de Kant, pueden abordarse como el intento de pensar -con Kant- una "política del espectador" que no niegue el peso de lo sucedido, ni sucumba mansamente a su peso. La facultad de juzgar viene a realizar la difícil tarea de convertir la "ruptura histórica" en "reflexión política". Lo cual quiere decir, reintegrar la política en el pensamiento y el pensamiento en la política.

\section{Eichmann y el juicio}


Más de diez años después de ¿Qué es Política?, Hannah Arendt indica, en las páginas finales de "El Pensamiento": "Al final nos encontraremos ante la última alternativa que puede haber en estas cuestiones -o bien decimos con Hegel: Die Weltgeschichte ist das Weltgericht, dejando el juicio último al éxito; o bien podemos reafirmarnos, con Kant, en la autonomía del espíritu humano y su capacidad de independizarse de las cosas tal como son o tal como han llegado a ser" (ARENDT, 2002, p. 235).

Según algunos intérpretes, estas palabras son el indicio de un cambio, que se puede hacer inteligible si nos concentramos en las Conferencias sobre Kant, en las que es posible encontrar una unidad respecto de una nueva preocupación arendtiana por el juicio, ligada a la figura del "espectador" fuera del juego que puede dar sentido a la de otro modo caótica parcialidad de los actores ( Cf. ARENDT, 2003, pp. 86-87, 104-105, 118-119).

De acuerdo con nuestra perspectiva, el problema es entender este "fuera de juego". Pues ya hemos indicado que la autonomía del juicio es central tanto en "Comprensión y Política" como en ¿Qué es Política?, en la medida en que es aquello que posibilita una distancia "reflexiva" respecto del peso de determinados acontecimientos: el totalitarismo entendido como abismo para comprensión, la modernidad entendida como "nihilismo". Aún cuando no esté mencionado con ese nombre, se trata del espectador de la política, que luego de la crítica arendtiana al "platonismo político" no podemos entender como una autoridad moral atemporal.

En consonancia con esto, el reporte del juicio de Eichmann permite a Arendt extraer las "consecuencias" de su anterior planteamiento. En el Postcriptum agregado a Eichmann en Jerusalen queda claro que las "lecciones" de esta experiencia están ligadas con la facultad de juzgar y su "autonomía".

Por una parte, se trata de la "autonomía" del juicio en tanto base para la atribución de responsabilidad personal bajo el totalitarismo9: "En estos procesos $(\ldots)$ se exigió que los seres humanos fuesen capaces de distinguir lo justo de lo injusto, incluso cuando para su guía tan solo podían valerse de su propio juicio, el cual, además, resultaba en total oposición con la opinión, que bien podía considerarse unánime, de cuantos le rodeaban. Los pocos individuos que todavía sabían distinguir el bien del mal se guiaban solamente mediante su buen juicio, libremente ejercido, sin la 


\section{4}

ayuda de normas que pudieran aplicarse a los distintos casos particulares con que se enfrentaban (...) porque ante los hechos sin precedentes no había normas" (ARENDT, 1967, p. 423).

Por otra parte, se trata de la autonomía del juicio en tanto sustento de la posibilidad de comprender y narrar acontecimientos históricos, tal como indica Arendt en la polémica que tiene con Scholem respecto de la posibilidad de "juzgar el pasado": "La argumentación según la cual aquellos que no estuvimos presentes e implicados en los acontecimientos no podemos juzgar parece convencer a la mayoría, en cualquier parte del mundo, pese a que es evidente que si fuera justa, tanto la administración de justicia, como la labor del historiador no serían posibles" (ARENDT, 1967, pp. 424-425).

\section{Las Conferencias sobre Kant}

Según lo dicho consideramos que las clases sobre Kant involucran un enriquecimiento del tema de la facultad de juzgar, producido por experiencias que Arendt piensa con el juicio -especialmente su asistencia al juicio en Jerusalen. Lo que según nuestra perspectiva no se modifica es el problema que está en la base de la apelación a la facultad de juzgar, problema que da inteligibilidad a la exclusividad de la fuente kantiana. Nos referimos a la demanda realizada por Arendt ya en "Comprensión y Política": la capacidad de juzgar tiene una originariedad que le permite una "autonomía situada". Esto es, es portadora de una autonomía respecto de "lo dado", que no significa un posicionamiento "por fuera" del ámbito de lo político como tal -que es también el ámbito de la historia en tanto "producto" de la acción. En este contexto, la lectura arendtiana de Kant brinda la base teórica para una idea de autonomía ligada a una "publicidad" del pensamiento (cuya ausencia, precisamente, está en la base de la irreflexión de Eichmann) que cualifica políticamente la tarea de pensar y comprender. Efectivamente, el concepto de "reflexión" kantiano, tal como es desarrollado en las Conferencias sobre la Filosofía Política de Kant, es una vía que le permite conservar, aunque de modo inestable, aquella distancia reflexiva entre "juicio" y contexto históricopolítico sin caer, sin embargo, en la jerarquía contemplativa de "los 
pocos" que en los años cincuenta diagnostica como el error fundamental de la filosofia política.

La tercera Crítica de Kant, aplicada por Arendt a la reflexión política, ofrece el espacio y la dirección general de un "pensamiento ampliado" que promueve la esfera pública al espacio de una reflexión cuya validez no descansa, ni en las formas universales y necesarias del conocimiento, ni en la "postulabilidad práctica" de nuestras máximas éticas ${ }^{10}$, sino en las condiciones de un ámbito intersubjetivo entre seres "sensibles y mundanos" -lo que Kant pensó como sensus communis. Arendt liga esta dimensión dialógica-discursiva del pensamiento (que no es una totalidad ética preexistente, sino un "ideal regulativo" capaz de poner en crítica el lugar del juicio privado) a una "imparcialidad desinteresada" propia de "espectadores reflexivos".

Ahora bien: ¿Qué significa esta "imparcialidad desinteresada”? Esta es la pregunta central. A riesgo de ser esquemáticos, diremos que la misma es expresión de una razonabilidad ligada al "particular"11, esencialmente vinculada al uso libre de la imaginación -en tanto facultad de hacer presente lo que está ausente ${ }^{12}$ - y que hace de la comunicabilidad la razón a priori de su funcionamiento ${ }^{13}$.

De acuerdo con los objetivos de este artículo, quisiéramos destacar que la facultad de juzgar involucra una "razonabilidad" que no abandona el mundo: es la distancia de la imaginación "reproductiva"14 aquello que está en su base. En este sentido, la "comunicabilidad", descansa en un procedimiento "íntimamente conectado con lo particular, las condiciones particulares a través de las que hay que pasar para poder llegar al propio 'punto de vista general' [...] nos referimos a esta perspectiva general como imparcialidad" (ARENDT, 2003, p. 85).

Creemos que a partir de este punto, se aclaran dos temas vinculados con la interpretación arendtiana.

Por una parte, las últimas dos páginas que las Conferencias dedican a la "ejemplaridad" como ámbito de validez del juicio. Según nuestra autora, esta es la solución más interesante que ofrece la Crítica del Juicio al problema de la ecuación entre imaginación y comunicabilidad: un aspecto importante del componente deliberativo del juicio, está ligado a la búsqueda de "ejemplos" que pudieran funcionar como "patrones" de juicio - particulares elevados, en su singularidad, al rango de ejemplares- 
para evaluar lo mejor y lo peor, respecto de nuestras acciones en el mundo, que es tanto como decir en la historia (ARENDT, 2003, pp. 141142) ${ }^{15}$. Esta "circularidad", por decirlo de algún modo, entre "particularidad" e "imaginación reflexionante" es aquello que estaría en la base de la "autonomía relativa" del juicio.

Por otra parte, en la medida en que se trata de la articulación entre la "imaginación" y una "comunicabilidad" que no está ligada a la "universalidad del concepto", la razón de ser de la deliberación potencial implicada en el juicio, no es ni puede ser el consenso -en tanto acuerdo racional asegurado a priori- sino la discusión misma, la disputabilidad respecto del mundo, así como respecto del propio sujeto de juicio -en tanto "sujeto al mundo". Este aspecto es central, pues permite articular las condiciones de posibilidad del pensamiento -eso que Arendt define como el diálogo del yo con el yo en numerosas oportunidades, y que Kant piensa bajo la idea de reflexión- con la política: "el pensamiento crítico, aunque siga siendo una ocupación solitaria, no se ha desvinculado de 'todos los demás' (...) Mediante la imaginación hace presentes a los otros y se mueve así potencialmente en un espacio que es público, abierto a todas partes; en otras palabras, se adopta la posición del ciudadano del mundo de Kant" (ARENDT, 2003, p. 8416).

\section{Eichmann reconsiderado}

De acuerdo con nuestra hipótesis, veamos ahora en qué medida la lectura arendtiana de Kant ilumina su libro sobre Eichmann, y amplia su reflexión acerca del juicio.

En primer lugar se encuentra la "lección" dada por Eichmann, pero también por su contrafigura. En páginas centrales del relato arendtiano, el acusado muestra una renuencia a juzgar de modo autónomo (ARENDT, 1967, p. 166). El punto fundamental es el siguiente: ¿Cómo se articula el diagnóstico arendtiano de un Eichmann banal, cuya característica más llamativa es la "irreflexión", con esta renuencia?; y subsidiariamente otra: ¿cuál es la estructura oculta que revelan los hombres de juicio, aquellos pocos que juzgaron? 
La lectura arendtiana de Kant, puede ayudarnos a comprender el análisis de la irreflexión de Eichmann que hace nuestra pensadora. Lo que subyace a esta irreflexión, es la distancia pasmosa entre el "significado subjetivo" de determinados actos - aquello que Arendt denomina su motivación autointeresada-, y su significado político y moral -que Arendt vincula precisamente con el ser capaz de pensar en el lugar de los otros (ARENDT, 1967, p. 77). La renuencia a "juzgar", en este caso, puede ser interpretada teniendo en cuenta su lectura de Kant: es la imposibilidad de ponerse como "espectador de sus propios actos" aquello que estaría en la base del colapso de la facultad de juzgar que es requerida por Hannah Arendt al final de su libro. El vínculo entre la autonomía del juicio y el espacio público, de claras raíces kantianas, nos permite ahora iluminar la "banalidad" de Eichmann ${ }^{17}$.Y no sólo de Eichmann.

Retomando el texto "Comprensión y Política", podemos afirmar lo siguiente. Arendt fue pronto consciente de que el surgimiento del mal político por excelencia debía ser leído en el contexto de una crisis sin precedentes en el juicio. Sin embargo, es el progresivo descubrimiento de la fuente kantiana aquello que le permite visualizar el punto exacto de la catástrofe. La "irreflexión" de Eichmann se convierte, en este horizonte, en el centro de una meditación acerca del corazón antipolítico de lo moderno y su utilización por parte de los gobiernos totalitarios. La desertización de lo público consumada por el totalitarismo, según lo dicho, no sólo alude a la detención de la estructura público comunicativa -como ya muestra en Los Orígenes del totalitarismo al distinguir el totalitarismo de la tiranía- ni sólo a la ausencia de "criterios comunes" para juzgar -como parece desprenderse del problema del fin de la tradición-, sino a la extinción del modo de reflexión que funciona como condición de posibilidad del juicio y que pudo convertir a un "ciudadano cumplidor de las leyes", en uno de los mayores criminales del siglo.

En este contexto, el inestable espacio político moderno sostenido exclusivamente por "la fuerza unificadora de las costumbres" -según nos indicaba Arendt en "Comprensión y Política", a partir del diagnóstico de Montesquieu-, aparece ahora como el lugar de una progresiva desintegración de la capacidad de la ciudadanía para alcanzar aquella perspectiva general implicada en la facultad de juzgar -cuya condición de posibi- 
lidad implica la liberación tanto de las idiosincracias personales como de los prejuicios colectivos.

Por otra parte, Arendt había indicado que incluso en una situación de juicio colectivamente corrupto, hubo unos pocos que conservaron intacta su capacidad de independizarse de las cosas "tal cual son o tal como han llegado a ser", y que esta habilidad debía ser vinculada a la autonomía del juicio. Bajo las condiciones imperantes en la Alemania nazi, donde lo público ya no coincidía con lo político, la lección dada por aquellos que resistieron al total colapso moral, es que el carácter potencialmente público de un modo de reflexión que hace de la comunicación con los otros un requisito a priori para su funcionamiento, "puede prevenir catástrofes", no solo para el yo, como indicaba Arendt respecto al pensar en "El Pensar y las consideraciones morales" (ARENDT, 1995, p. 137), sino para el mundo18.

Finalmente. Es en la polémica con Scholem donde aparece un último aspecto que puede ser reconducido claramente a las inquietudes de los años cincuenta.

La publicación de Eichmann en Jerusalen envolvió a Hannah Arendt en un extenso e irritado debate. Refiriéndose al juicio de nuestra pensadora sobre los consejos judíos, Gershom Scholem señala que lo sucedido -y decidido- "en circunstancias que no podemos siquiera intentar reproducir o reconstruir", no pueden ni deben juzgarse (ARENDT, H., 2005b, p. 140).

La respuesta de Arendt indica que lo que está en el fondo de esta disputa es un desacuerdo importante sobre la naturaleza y función del juicio y sobre su articulación con el problema de la comprensión humana (Cf. ARENDT, 2005b, p. 141). El gran tópico de esta polémica está vinculado al "uso público" del propio juicio de Arendt y, más generalmente, a las relaciones entre acción humana, autonomía del juicio y comprensión histórica. Bajo la luz de sus últimas afirmaciones sobre la facultad de juzgar, tal como se desarrollan en las Conferencias sobre la Filosofía Política de Kant, así como en el Postscriptum a "El Pensamiento", es posible advertir que lo que Arendt tiende progresivamente a pensar bajo la figura del espectador cosmopolita kantiano es la necesidad imperiosa de una relación "reflexiva" con el pasado. Una preocupación que es estrictamente política, y que ocupa la entera obra 
de Arendt. En este marco, la apelación a la facultad de "hacer presente lo que está ausente" -tal como se desarrolla en las Conferencias-, forma parte de lo que Arendt advierte como el gran peligro presente en la renuencia de sus co-espectadores a alcanzar este "punto de vista general": la mitologización del horror. En este plano, su relato del proceso Eichmann, no estaba orientado por una "simpatía" ni hacia el acusado ni por una "falta de simpatía" hacia las víctimas, sino por el intento de comprender este horror en unos términos que lo hicieran juzgable $-\mathrm{y}$ disputable ${ }^{19}$. Lo cual quiere decir: aunque los acontecimientos que él había ayudado a desencadenar parecieran, y aún parezcan, quedar más allá del entendimiento humano, esto no les otorgaba la dignidad de una significación metafisica, ni separaba totalmente al criminal del entendimiento (Cf. BARNOW, 1991, p. 19).

\section{A modo de conclusión}

Más de diez años después del juicio de Eichmann, Hannah Arendt culmina las páginas finales de "El Pensamiento" con una apelación a Kant, lo que implica una apelación a "la autonomía del espíritu humano y su capacidad de independizarse de las cosas tal como son o tal como han llegado a ser". El principio político involucrado en este ejercicio queda resumido en la frase de Catón, que esta pensadora planifica incorporar como epígrafe a la tercera parte del volumen:Victix causa deis placuit, sed victa Catoni (ARENDT, 2002, p. 236) 20.

Para concluir quisiera al menos sugerir una interpretación, precisamente tomando como hilo conductor la frase de Catón, citada por Lucano. Según la misma, La Vida del Espíritu resulta la "respuesta" arendtiana final a aquello que definimos como la posibilidad de un pensamiento de la política ${ }^{21}$. Si, tal como indica en las Conferencias sobre la filosofía política de Kant, el objeto de la Filosofia Política no es ni ha sido "la polis o su política sino la relación entre filosofía y política", la facultad de juzgar ofrece a Hannah Arendt la posibilidad de una crítica de la razón política que involucra una redefinición de las relaciones entre el pensar, la política y la historia. Esto representa, desde nuestra perspectiva la posibilidad del espectador kantiano. 
El espectador es la otra cara del actor, sólo en la medida en que aborda políticamente la historia -no ya como lugar del despliegue de una identidad del espíritu o de la especie, como un "todo significativo", sino como el escenario de una diferencia y de una libertad que tiene un sentido inagotable respecto de lo "efectivamente acontecido". Respecto, diríamos, al éxito o al fracaso. Pero también, diríamos, sin olvidar los éxitos y los fracasos. En este horizonte, la autonomía mundana de la facultad de juzgar es el privilegio humano de disputar el presente, encontrando "mensajes" -"ejemplos"- de libertad política en el fracaso, y de servidumbre en el éxito. Un "momento ilustrado" de la tragedia y una renuencia trágica de la ilustración.

No deja de ser interesante pensar en la contemporaneidad de Arendt, en sociedades y filosofias demasiado complacientes con los triunfos de la libertad respecto del pasado totalitario, y menos atentas a los "mensajes" del éxito de éste último.

${ }^{1}$ El presente artículo revisa y amplía algunos de los motivos del texto de nuestra autoría "Juzgar", a ser publicado próximamente en el Vocabulario Hannah Arendt en la editorial Homo Sapiens, Argentina. Agradezco los lúcidos comentarios y críticas de la Dra Yara Frateschi (Unicamp).

${ }^{2}$ Al momento de su súbita muerte, en 1975, fueron encontrados en su máquina de escribir sólo un título - El Juicio- y dos epígrafes, uno de Lucano y otro de Goethe. Mary McCarthy, encargada de la conversión editorial de las Conferencias Gifford (dictadas por Arendt entre 1972 y 1974 y referidas hasta ese momento al pensar y la voluntad) en la obra póstuma, La Vida del Espíritu, agregó a la misma un apéndice que contenía un resumen de las notas preparadas por Arendt para un curso dictado en la New School en el otoño de 1970, sobre la Filosofia política de Kant. Son estas notas las que posteriormente fueron editadas en toda su extensión por Ronald Beiner bajo el título Lectures on Kant's Political Philosophy. En el caso de las obras de Arendt citaremos las ediciones en español. En la bibliografía final indicamos las primeras ediciones de todas las obras y artículos citados.

${ }^{3}$ Nuestra hipótesis general implica un posicionamiento respecto a una de las grandes polémicas respecto al juicio en la obra de Arendt. El centro de la disputa reside en la posibilidad -planteada entre otros por Ronald Beiner- de hablar de dos "teorías" del juicio en la obra de Arendt. Según esta interpretación, sería posible establecer un corte entre la meditación arendtiana de los sesenta, que intenta pensar el juicio como una facultad práctico-política de los actores, y la reflexión de los setenta, en la que la actividad de juzgar quedaría reservada exclusivamente al espectador "fuera del juego" que contempla el curso histórico del mundo. Como iremos señalando progresivamente, consideramos que este modo de abordar el juicio involu- 
cra una dicotomía estéril, que no tiene suficientemente en cuenta la continuidad problemática de la reflexión arendtiana respecto a este tema. El punto fundamental, a nuestro entender, es que el juicio es la posibilidad de una distancia -y en ese punto es siempre juicio del espectador. Lo central es el carácter potencialmente "político" de la misma, que Arendt desarrolla con su reflexión acerca de Kant durante los años sesenta y setenta. Los dos textos canónicos respecto a la primera postura son: BEINER, R., 2003; BERNSTEIN, R., 1991. En otra tradición, con una lectura a nuestro entender más compleja, también: DENNENY, M., 1994. Entre los teóricos que defienden una unidad en la reflexión arendtiana sobre el juicio, hay que destacar la sólida argumentación deVILLA, D., 1999. Respecto a esta última interpretación, si bien coincidimos en que existe una continuidad en la reflexión arendtiana sobre este tema, no acordamos en que esta continuidad muestra el carácter "no político" del juicio desde el inicio (o más bien su rol sólo "preventivo" respecto al mundo de la política), sino al contrario.

4 Esta "crítica" no implica un "desconocimiento de los hechos". Tal como intentamos desarrollar en este artículo, la facultad de juzgar ofrece precisamente un procedimiento críticoimaginativo que no hace simplemente una "abstracción" respecto a lo dado, sino que más bien hace posible una "comprensión crítica" que definimos a partir del concepto de "autonomía relativa" o de "imparcialidad situada". Respecto del dificil problema de las vinculaciones entre "verdad" y "narración", encontramos altamente estimulante el artículo de ENAUDEAU, C., 2007, p. 1036. En este horizonte, creemos, debe abordarse el dificil texto: ARENDT H., 1996c.

${ }^{5}$ Hannah Arendt a Mary Underwood, 24 de septiembre de 1946.

${ }^{6}$ Según su biógrafa, el éxito de la Introducción a la Filosofía de Jaspers, publicada en 1950, llevó a K. Piper a proponer a Arendt, en 1955, una Introducción a la Política. También se sugiere que en la medida en que Arendt se refirió a este libro a veces como Einleitung in die Politik y a veces como Einführung in die Politik, podría haberlo pensado como una réplica a Heidegger, Einführung in die Metaphysik.

7 Tal como indica la pensadora: "La imparcialidad homérica descansaba en la aceptación de que las grandes cosas son evidentes por sí mismas, brillan por sí mismas; de que el poeta (el historiador, más adelante) sólo tiene que conservar esa gloria de las cosas, que en sí es fútil y que él destruiría, en lugar de conservarla, si se olvidara de la gloria que le correspondió a Héctor”, ARENDT, 1996b, pp. 60, 226 y 236.

${ }^{8}$ En esta afirmación de Arendt está presente la distinción kantiana entre discusión y disputa, tal como es establecida en la resolución a la Antinomia del gusto, expuesta en la Dialéctica de la Facultad de Juzgar Estética. Para este punto ver KANT, 1991, \56, p. 245.

9 Cf. todos los ensayos incluidos en ARENDT, 2007.

10 Como es posible advertir desde la carta a Jaspers, la atracción de nuestra pensadora por la Tercera Crítica sólo es comparable con su igual rechazo de la Crítica de la Razón Práctica. Hay que tener mucho cuidado, sin embargo, sobre la óptica arendtiana respecto de la filosofía moral kantiana. Su crítica al imperativo categórico está ligada al hecho de que con el concepto de deber -y el correlativo de obligación-, el pensador alemán introduce por la puerta trasera un "platonismo político" que oculta los supuestos más radicales de su filosofia -que para Arendt es una filosofia de la libertad. Tal como indica en un texto fundamental y sólo 
recientemente investigado, la critica de la ética kantiana no le impide reconocer su aspecto rebelde, no sólo evitado en general por los intérpretes sino por cierto kantismo de uso doméstico del que hará uso -de modo insospechado-, el propio Eichmann. La rebelión kantiana reside en el hecho de que el pensador atribuye a todos los hombres la capacidad de legislar y juzgar más que la de obedecer unas normas pre-establecidas. Aquí se ilumina la politicidad de la ética. Para este punto ver: ARENDT, 2007, pp. 90-95. Respecto al "kantismo" de uso doméstico de Eichmann ver, ARENDT, 1967, p. 195-199.

11 Este aspecto será reiteradamente señalado en las Conferencias: "la facultad del juicio se ocupa de lo particular, lo cual, 'como tal encierra algo contingente con respecto lo universal', de lo que se ocupa normalmente el pensamiento” (ARENDT, 2003, p. 33). Cf. KANT, 1991, Primera Introducción, Sección IV, p. 90. Es esto lo que define el paralelismo central entre el juicio estético y el juicio político sobre la revolución francesa (ARENDT, 2003, p. 87 y ss).

12 La imaginación "transforma un objeto en algo con lo que no me he enfrentado directamente, pero que de alguna forma he interiorizado, de manera que ahora me puede afectar como si me hubiese sido proporcionado por un sentido no objetivo". La clave de la interpretación, reside en el modo en que esta pensadora describe la "distancia estética" posibilitada por el proceder imaginativo: "Solo lo que conmueve y afecta en la representación [...] puede ser juzgado luego como bueno o malo, importante o irrelevante, bello o feo, o algo intermedio. Entonces se llama juicio y ya no gusto (...) Al distanciarse el objeto, se establecen las condiciones para la imparcialidad” (ARENDT, 2003, p. 124-125). Cf., KANT, 1991, \$ 45, p. 216)

13 La operación de la imaginación prepara para "la operación real de juzgar algo", pues mientras el objeto se retira de los sentidos externos, se convierte ahora en un objeto de los sentidos internos [...] El sentido del gusto es un sentido en el que parece que uno se siente a sí mismo, un sentido interno" -indica Arendt. Y el juicio se llama gusto porque "escoge". ¿Cómo lo hace? Esta misma elección está sujeta a otra elección: "Nos place el mismo acto de la aprobación, el mismo acto de la desaprobación nos disgusta”. Cf. KANT,1991, $\$$ 54; p. 238. ¿Cuál es el criterio que guía a la operación judicativa? El criterio, dirá la autora, es "la comunicabilidad o publicidad" de nuestros placeres y displaceres; y lo que hace esto posible es lo que Kant anuncia en el parágrafo 20 y desarrolla en el 40, como el proceder de un "sentido común", que es necesario presuponer en la general comunicabilidad del placer en lo bello, (ARENDT, 2003, pp. 127-129). Cf. KANT,1991, \22; p. 154 y \40; p. 204-205.

14 Pocos trabajos abordan este aspecto fundamental. Es la distinción entre imaginación productiva y reproductiva la que Arendt utiliza para contraponer la singularidad sublime del "genio" y la generalidad del gusto respecto de lo bello, así como la primacía del segundo sobre el primero, dado que la facultad del gusto es aquello que comparten el artista y el crítico, el "actor" y el "espectador" (ARENDT, 2003, pp. 116-119). Cf. YOUNG-BRUEHL Y KOHN, 2007, pp. 1045-1049. Cf. KANT, 1991, \ 48, p. 221.

15 También el apartado "Imaginación” agregado a las Conferencias por Ronald Beiner.

16 El corolario que subyace para Arendt a esta vinculación, es que el principio del juicio estético tiene como su consecuencia la libertad de hablar y publicar. Lo que diferenciaría el planteo kantiano en este punto, y que definiría precisamente su radicalidad es que el "uso público de la razón” es una condición de posibilidad de la crítica misma. Cf, ARENDT, 2003, pp. $67-80$.

doispontos, Curitiba, São Carlos, vol. 7, n. 4, p.105-126, setembro, 2010 
17 Cf. ARENDT, 2003, p. 140, en donde Arendt precisamente indica la posibilidad de una perversión del sensus communis en un sensus privatus, "un sentido privado que Kant llama también Eigensinn lógico", que funcionaría sin la comunicación con los otros.

${ }^{18}$ Tal como indica la pensadora: "Para los juicios del gusto, el objeto primordial, es el mundo, no el hombre ni su vida ni su yo”, ARENDT, 1996a, p. 234.

19 No deja de ser relevante que Arendt apele en este epistolario al selbstdenken de Lessing. Precisamente en su texto sobre éste, Arendt indica un modo de entender el diálogo como polémica, que creemos debe ser leído junto con su recuperación del "otro Kant", ARENDT, 1990, pp. 40. Si bien en este texto hemos acentuado la vinculación de la reflexión arendtiana con el problema de la comprensión histórica planteado en Eichmann, consideramos que se puede pensar bajo las mismas coordenadas el intento arendtiano de pensar la "herencia sin testamento" de las revoluciones modernas. Por otra parte, este problema no es ajeno a la meditación sobre el totalitarismo, como muestra el hecho de que es la reflexión sobre el stalinismo y su compleja relación con Marx lo que abre toda la obra arendtiana de los cincuenta En este marco, es significativo que a la segunda edición de Los Orígenes se agregue un apéndice sobre la "causa derrotada" de la revolución húngara y de su enorme significado -más allá del criterio del éxito, según la frase de Hegel a la que Arendt contrapondrá la autonomía kantiana y el pathos republicano de Catón. Tal autonomía, en este contexto, implica también una libertad para cuestionar los modos mismos de evaluar los éxitos y los fracasos de la revolución, en el marco de sociedades postotalitarias. Desde esta perspectiva, un texto como Crisis de la República puede verse como el intento polémico de vincular el "éxito" de la república norteamericana con sus raíces democrático revolucionarias y su "fracaso" con el olvido de esta tradición por causa de una interpretación liberal de las instituciones republicanas. Leído sobre el trasfondo de su libro sobre Eichmann, las palabras de Arendt son también una advertencia respecto a los usos que el totalitarismo hace de aquella interpretación.

20 "La causa victoriosa place a los dioses, pero la causa vencida le place a Catón".

21 Con esto no pretendemos desconocer la nueva visibilidad y complejización de la "vida del espíritu" sino situarla en el contexto de las preocupaciones políticas y morales de los cincuenta y sesenta, dado que consideramos que existen numerosos textos que intentan pensar lo que Arendt "hubiera dicho" en el inconcluso Juzgar, sólo teniendo en cuenta los problemas inmanentes a La Vida del Espíritu.

\section{Referências bibliográficas}

ARENDT, H., 1967, Eichmann en Jerusalén. Un estudio sobre la banalidad del mal, Barcelona, Lumen. Trad. Carlos Ribalta (1 ed., 1963, Eichmann in Jerusalem: A Report on the Banality of Evil, New York, Viking Press; $1965,2^{a}$ ed. revisada y ampliada) 
ARENDT, H., 1990, "Sobre la humanidad en tiempos de oscuridad. Reflexiones sobre Lessing”, en ARENDT, Hombres en tiempos de oscuridad, Barcelona, Gedisa, pp. 13-41. Trad. de Claudia Ferrari (1 $1^{\mathrm{a}}$ ed., 1960, Von der Menschlichkeit in Finsteren Zeiten: Gedanken zu Lessing, Hamburgo, Hauswedell)

ARENDT, H./ JASPERS, K., 1992, Hannah Arendt Karl Jaspers, Correspondence 1926-1969, New York, Harcourt Brace \& Company.

ARENDT, H., 1993, La Condición Humana, Barcelona, Paidós. Traducción: Rosa Sola Carbó (1 ${ }^{a}$ ed., 1958, The Human Condition, Chicago, University of Chicago Press)

ARENDT, H., 1994a, Los Orígenes del Totalitarismo, Barcelona, PlanetaAgostini. Trad. Guillermo Solana ( $1^{\mathrm{a}}$ ed., 1951, The Origins of Totalitarianims, Nueva York, Harcourt, Brace \& Co. $2^{\mathrm{a}}$ ed. ampliada, 1958, Nueva York, World Publishing Co., Meridian Books. $3^{a}$ ed. con nuevos prefacios, 1966, 1968, 1973, Nueva York,. Harcourt, Brace \& World)

ARENDT, H., 1994b, “Comprensión y Política”, en HILB, C., (comp.), El resplandor de lo público. En torno a Hannah Arendt, Caracas, Nueva Sociedad, pp. 29-46. Trad. de Viviana Quiñones (1 a ed., 1953, "Understanding and Politics", Partisan Review, New York, XX/4, pp. 377-92 )

ARENDT, H., 1995, “El Pensar y las consideraciones morales”, en CRUZ, M., ( comp), Hannah Arendt. De la historia a la acción, Barcelona, Paidós, pp. 417-446. Trad. de Fina Birulés (1 $1^{\text {a }}$ ed., 1971, “Thinking and Moral Considerations: A Lecture”, Social Research, New York, 38/3, pp. 417-46)

ARENDT, H., 1996a, "Crisis en la cultura: su significado político y social" en ARENDT, Entre el pasado y el futuro, Barcelona, Península, pp. 209-238. Trad. de Ana Poljak (1 ${ }^{\mathrm{a}}$ ed, 1960, "Society and Culture", Daedalus, 82/2, pp. 278-87)

ARENDT H., 1996b, "El concepto de historia: antiguo y moderno", en ARENDT, Entre el pasado y el futuro, Barcelona, Península, pp. 49- 
100. Trad. de Ana Poljak (1 $1^{\mathrm{a}}$ ed., 1958, “The Modern Concept of History”, Review of Politics, 20/4, pp. 570-90)

ARENDT H., 1996c, "Verdad y Política", en ARENDT, Entre el pasado y el futuro, Barcelona, Península, pp. 239-277. Trad. de Ana Poljak (1 ${ }^{\text {a }}$ ed., 1967, “Truth and Politics", New Yorker, pp. 49-88)

ARENDT, H., 1997, ¿Qué es Política?, Barcelona, Paidós. Trad. de Rosa Solá Carbo (1ª ed., 1993, Was ist Politik?, Munich, Piper)

ARENDT, H., 2002, La Vida del Espíritu, Buenos Aires, Paidós. Trad. de Carmen Corral y Fina Birulés (1 $1^{a}$ ed., 1978, The Life of Mind, Nueva York, Harcourt Brace Jovanovich)

ARENDT, H., 2003, Conferencias sobre la filosofía política de Kant, Barcelona, Paidós. Trad. de Carmen Corral (1ª ed., 1982, Lectures on Kant's Political Philosophy, Chicago, University of Chicago Press) ARENDT, H., 2005a, “Una réplica a Eric Voegelin”, en ARENDT, Ensayos de Comprensión 1930-1954, Madrid, Caparrós, pp.483-491. Trad. de Agustín Serrano de Haro (1ª ed., 1953, "Rejoinder to Eric Voegelin's Reviews of The Origin of Totalitarianism", Review of Politics, 15, pp. 76-85)

ARENDT, H., 2005b, "Eichmann en Jerusalen. Intercambio epistolar entre Gershom Scholem a Hannah Arendt", en ARENDT, Hannah Arendt, Una revisión judía y otros ensayos, Buenos Aires, Paidós, pp. 137150. Trad. de Miguel Candel (1 $1^{\text {a }}$ ed., 1964, "Eichmann in Jerusalem”, Encounter, enero, pp. 51-56)

ARENDT, H., 2007, “Algunas cuestiones de filosofia moral” en ARENDT, Responsabilidad y juicio, Barcelona, Paidós, pp. 75-150. Trad. de Miguel Candel (Texto inédito de 1966, 1ª ed., 2003, "Some Questions of Moral Philosophy", ed. Jerome Kohn, New York, Schocken Books, pp. 49-146)

BARNOW, D., 1991, "Hannah Arendt, el discurso de la modernidad y la construcción de lo político", Debats, N³7, Septiembre, pp. 19-26. 
BEINER, R., 2003, “Ensayo Interpretativo. Hannah Arendt y la facultad de juzgar", en ARENDT, H., Conferencias sobre la filosofía política de Kant, Barcelona, Paidós.

BERNSTEIN, R., 1991, “¿Qué es juzgar?. El actor y el espectador”, en Perfiles Filosóficos. Ensayos a la manera Pragmática, México, Editorial Siglo Veintiuno.

BOELLA, L., 2000, “¿Qué significa pensar políticamente?”, en BIRULÉS F., (comp.), Hannah Arendt. El Orgullo del Pensar, Barcelona, Gedisa.

DENNENY, M., 1994, "El privilegio de nosotros mismos: Hannah Arendt y el juicio”, en HILB, C., (comp.), El Resplandor de lo Público, Caracas, Nueva Sociedad.

ENAUDEAU, C., 2007, "Hannah Arendt: Politics, Opinion, Truth", Social Research, New York, Vol. 74, N 4, pp. 1029-1044.

KANT, E., 1991, Crítica de la Facultad de Juzgar, Caracas, Monte Avila. Trad. de Pablo Oyarzún (KANT, [1791], 1902-1975, Gesamtausgabe, Berlín, Königlichen Preussisschen Akademie der Wissenschaft, vol.V)

VILLA, D., 1999, “Thinking and Judging”, en HERMSEN, J., \& VILLA, D., (eds.), The Judge And The Spectator. Hannah Arendt's Political Philosophy, Editorial Peeters, Bélgica.

VOLLRATH, E., 1994, “Actuar y Juzgar. Hannah Arendt y la lectura de la Crítica del Juicio de Kant desde una perspectiva política”, en HILB, C., (comp.), El resplandor de lo público. En torno a Hannah Arendt, Caracas, Nueva Sociedad.

YOUNG-BRUEHL, E., y KOHN, J., 2007, “On Truth, Lies and Politics. A Conversation”, Social Research, New York,Vol. 74, N 4, pp. 1045-1070.

YOUNG-BRUEHL, E., 1993, Hannah Arendt,Valencia, Alfons El Magnànim. 